\title{
Correction to: A systematic review of the effects of low-frequency repetitive transcranial magnetic stimulation on cognition
}

\author{
Claudia Lage $^{1} \cdot$ Katherine Wiles $^{2} \cdot$ Sukhwinder S. Shergill ${ }^{1,3} \cdot$ Derek K. Tracy $^{1,4}$
}

Published online: 21 June 2019

(c) The Author(s) 2019

\section{Correction to: J Neural Transm (2016) 123:1479-1490 https://doi.org/10.1007/s00702-016-1592-8}

The original version of this article unfortunately contained a mistake. The author would like to include the below acknowledgement section.

Acknowledgements Professor Sukhi Shergill was funded by an ERC Consolidator Award.

Open Access This article is distributed under the terms of the Creative Commons Attribution 4.0 International License (http://creativeco mmons.org/licenses/by/4.0/), which permits unrestricted use, distribution, and reproduction in any medium, provided you give appropriate credit to the original author(s) and the source, provide a link to the Creative Commons license, and indicate if changes were made.
Publisher's Note Springer Nature remains neutral with regard to jurisdictional claims in published maps and institutional affiliations.

The original article can be found online at https://doi.org/10.1007/ s00702-016-1592-8.

Derek K. Tracy

derek.tracy@oxleas.nhs.uk

Katherine Wiles

katherine.wiles@kcl.ac.u

1 Cognition, Schizophrenia and Imaging Laboratory, The Institute of Psychiatry, Psychology and Neuroscience, King's College London, London, UK

2 King's College London School of Medicine, London, UK

3 South London and Maudsley NHS Foundation Trust, London, UK

4 Oxleas NHS Foundation Trust, London, UK 